\author{
III. Aus der Uniyersitätsklinik \\ für Dermatologie und Syphilis in Turin. \\ (Direktor: Prof. Dr. Giovannini.)
}

\section{Ein Fall von Quecksilberintoxication mit Scharlacherythem nach hochdosirter Sublimatinjection.}

Von Dr. V. Allgeyer und Dr. F. Sprecher, Assistenten.

Bekanntlich sind durch Oestreicher, Lassar und Lukasiewicz hochdosirte Sublimatinjectionen in die Syphilistherapie eingeführt worden. Weder diese Autoren, noch Andere, die ihre Methode zur Anwendung brachten, liaben bedrohliche Folgeerscheinungen nach solchen Einspritzungen zu beobachten gehabt. Wir hatten dagegen Gelegenheit, bei einer mit denselben angestellten Reihe von Versuchen an den Kranken der Klinik eine schwere Intoxication mit Scharlacherythem zu constatiren, und halten es daher für zweckmässig, den Fall zı veröffentlichen, besonders weil derselbe zur Vorsicht mahnt und die mit Exanthem verbundenen Intoxicationen nach Sublimateinspritzungen überhaupt zu den Seltenheiten gehören.

Patientiu ist eine 17 Jahre alte Puella, von mubekannten Eltern stammend, von mittlerer Statur und regelmässigem Körperbaı.. Muskelsystem normal, Fettpolster nur mässig entwickelt. Ihr Ausselien ist das einer gesunden ind kräftigen Person. An den Streckseiten der Glieder und am Rücken besteht eine Cheratosis pilaris leichten Grades. Die Menses begannen im elften Lebensjahre und waren bis zum hentigen Tage immer von starkeu dysmenorrhoischen Schmerzen begleitet. Seit dem Alter von 14 Jahren leidet Patientin an hysterischen Anfällen. Im October 1894 erfolgte Syphilisinfection.

Am 16. December desselben Jahres kam sie wegen syphilitischer Erosionen an den Lippen und einem mit Leistenbubo complicirten venerischen Geschwilr an der Commissura posterior auf die Klinik. Da sie noch keine antisyphilitische Cur durchoemacht hatte, wurde nun eine solche mit hochdosirten intramuskulären Sublimatinjectionen eingeleitet. Znerst kam für jede Einspritzung eine Dosis von $3 \mathrm{cg}$ zur Anwendung. Diese Injectionen wurden wie gewöhnlich in der Glutäalgegend an den Ëlectionsstellen vorgenommen. Damals konnte aber die Behandlıng nicht weitergeführt werden, da Patientin nach Abheilung ihres Bubo die Klinik verlassen wollte, uachdem nur zwei Injectionen, die sehr gut vertragen wurden, in Abstande einer Woche gemacht worden waren.

Am 17. Januar 1895 kehrte Patientin mit denselben Schleimhautaffectionen in die Klinik zurück. Die unterbrochene Behandlıng wurde wieder aufgenommen; dieses Mal aber erhöhte man die Dosis, indem ihr alle acht Tage $4 \mathrm{cg}$ Sublimat eingespritzt wurden. Sie erhielt drei solcher Injectionen, und auch diese wurden ausgezeichnet vertragen: das Mädchen versicherte, sich sehr wohl zil fuhlen, und im Harn konnte keine Spur Eiweiss nachgewiesen werden. Wir hielten uns daher fü berechtigt, zu einer Injection von $5 \mathrm{cg}$ überzugehen.

Dieselbe wurde am 21. Februar gegen 10 Uhr Morgens, eine Woche nach der letzten Injection von $4 \mathrm{cg}$, wie immer unter strenger Beobachtung aller antiseptischen Maassregeln in der Glutäalgegend vorgenommen. Von Blutung keine Spur. Jedoch dieses Mal kam es bald zu schweren Intoxicationserscheinungen. Schon in den ersten Nachmittagsstunden begann Patientin über starke Halsbeschwerden, Metallgeschmack und Speichelfluss zu klagen. In der Nacht heftige Kolikschmerzen und mehrere seröse Stühle. Ausserdem überkan sie starker Schiittelfrost und ein peinliches Beklemmungsgefïhl.

Am folgenden Tage zeigte sich an Brust und Hals ein Erythem von äusserst lebhafter Farbe. Von einer gewissen Entfernung gesehen, erschien die Röthe gleichmässig, bei näherer Besichtigung jedoch intensiver an den etwas hervorstehenden Haarfollikeln, so dass das Exanthem ein auffallend punktförmiges Aussehen annahm. Dabei hielten starke Kopfschmerzen an. Da die durch die Stomatitis hervorgerufenen Beschwerden und dic Halsschmerzen zulgenommen hatten, konnte die Kranke kaum sprechen und nur mit grosser Mühe ein wenig den Mund öffnen. Die T'emperatur betrug des Morgens 38,4 ${ }^{\circ}$ und erreichte am Abend ein Maximum von $39,6^{\circ}$. Puls 130 . Der Harn war in geringer Quantität, trübe, von röthlicher Farbe und stark eiweisshaltig.

Anı dritten Tage verschlimmerte sich der Zustand der Patientin weiter. Das Erythem breitete sich fast über den ganzen Körper aus. Mitten in der Röthe des Gesichts hob sich um Nase und Lippen eine Zone blasser Haut ab. Der Durchfall hielt wie am zweiten Tage mit obell genanntem Charakter an. Der Druck anf den ganzen Uuterleib war schmerzhaft, besonders aber in der Ileocoecalgegend. Die T'omperatur stieg Abends auf $40^{\circ}$, Puls 140. Im Harn hatte die Eiweissmenge stark 
zugenommen; ausserden fand sich eine enorme Quantität Cylinder, meist hyaliner Natur, nebst vielen L Leukocyten.

Am vierten Tage gelang es zum ersten Male, wenı auch mit vieler Mühe, den Mund zu untersuchen. Es zeigte sich eine schwere, zum Theil ulcerös gewordene Stomatitis; ausserdem das charakteristische Bild der Himbeerzunge. Auffallend war besonders der Befund der Tonsillen: diese waren theilweise mit schmierigem, weisslichem Belag bedeckt und so angeschwollen, dass nur ein enger Spalt zwischen ihnen übrig blieb. Die Kranke fühlte sich äusserst schwach und verlor bei der kleinsten Bewegung das Bewusstsein, sonst war sie immer bei sich und delirirte auch im höchsten Fieber nicht. Gegen Abend verfiel sie in einen comatősen Zustand. Das Fieber scliwankte zwischen $39^{\circ}$ und $40^{\circ}$, die Zahl der Athemzüge in der Minute zwischen 35 und 45. Puls 135. Letzterer war sehr klein. Ein Collaps war zu befürchten. Urinbefund und Durchfall blieben unverändert. Die Untersuchung der Lungen, des Herzens und der Milz ergab nichts Bemerkenswerthes. Der Schmerz, der an der Injectionsstelle unmittelbar vorhanden war, verschwand nun. In diesen vier Krankheitstagen hatte Patientin nur wenige Löffel Milch zu sich nehmen können.

Glïcklicherweise besserte sich gegen Morgen des fünften Tages das Befinden der Kranken in auffallender Weise: der Kopfschmerz nahm ab, die Ohnmachten wurden seltener, ebenso die flüssigen Stühle. Das Erythem begann abzublassen. Jedoch erreichte die Abendtemperatur noch ein Maximum von $39,9^{\circ}$, und der Harn blieb noch immer stark eiweisshaltig.

Am sechsten Tage machte die Besserung noch weitere Fortschritte. Das Erythem war am Rumpf und im Gesicht fast ganz verschwunden, und es hatte sich eine reichliche, kleienförmige Abschuppung eingestellt. Die Temperatur ïberschritt nicht $38,5^{\circ}$.

Am siebenten Tage war die Kranke fieberlos. Von diesem T'age an gingen die Intoxicationssymptome rasch zurück. Die kleienformige $\mathrm{Ab}$ schuppung erstreckte sich auch auf die Glieder, hier jedoch in geringerem Grade. Die Eiweissmenge des Harns nahm von Tag zu Tag ab, und am zwölften Tage nach der Injection war kein Albumen in demselben mehr nachweisbar. Auch die Durchfälle, die nie blutig gewesen waren, hörten auf. Die Stomatitis hielt von allen Erscheinungen am längsten an, doch war sie ganz verschwunden, als Patientin 22 Tage nach der Injection die Klinik verliess.

Wir hatten noch Gclegenheit, das Mädchen vier Monate nach der Injection im besten Gesundheitszustande wiederzusehen.

Es ist also in diesem Falle nach einer intramuskulären Injection von $5 \mathrm{cg}$ Sublimat eine schwere Quecksilberintoxication eingetreten. Sie zeigt sich in ihrem gewöhnlichen Bilde; von besonderem Interesse sind jedoch das typische Scharlachery them und die hochgradige Angina, die sich als spezielle Reaction des Organismus hinzugesellten. 